\title{
Screening for IgG4-type anti-nuclear antibodies in lgG4-related disease
}

Kazuhiro Kiyama, Hajime Yoshifuji', Tsugumitsu Kandou, Yuji Hosono, Koji Kitagori, Ran Nakashima, Yoshitaka Imura, Naoichiro Yukawa, Koichiro Ohmura, Takao Fujii, Daisuke Kawabata and Tsuneyo Mimori

\begin{abstract}
Background: Immunoglobulin (Ig) G4-related disease (IgG4-RD) is characterized by elevated serum IgG4 and infiltration of $\operatorname{lgG} 4^{+}$plasma cells into multiple organs. It is not known whether serum lgG4 is autoreactive in IgG4-RD.

Methods: We measured anti-nuclear antibody (ANA) in 19 lgG4-RD cases, determined lgG subclasses of the ANA, and compared them with those of other systemic autoimmune diseases (systemic lupus erythematosus, Sjögren's syndrome, systemic sclerosis, and polymyositis), using subclass-based ANA test (indirect immunofluorescence).

Results: $58 \%$ of IgG4-RD cases were ANA-positive (cut-off: 1:40). Whereas their subclass of ANA was predominantly lgG2, we observed no lgG4-type ANA. In systemic autoimmune diseases, subclasses of ANA were mostly lgG1, 2, or 3, but lgG4-type ANA was very rarely detected. We also found several patients in whose serum ANA patterns differed among lgG subclasses, probably due to the difference of corresponding autoantigens.

Conclusions: Although lgG4 is highly elevated in sera of lgG4-RD patients, their ANA do not include lgG4 subclass. These results offer new insight into the role of IgG4 and the pathogenesis of IgG4-RD, implying that each IgG subclass tends to cover its own spectrum of antigens, and lgG4 is not preferentially used to make ANA.
\end{abstract}

Keywords: IgG4-related disease, Systemic autoimmune disease, IgG subclass, Autoantibody, Anti-nuclear antibody

\section{Background}

Immunoglobulin (Ig) G4-related disease (IgG4-RD) is a multi-organ disorder characterized by elevated serum IgG4, organ infiltration by IgG4 ${ }^{+}$plasma cells, hypergammaglobulinemia, and tissue sclerosis [1-4]. Many organs, such as lacrimal gland, salivary gland, eye orbit, lymph node, thyroid gland, lung, pancreas, kidney, retroperitoneum, and prostate can be affected by IgG4-RD. The role of IgG4 in IgG4-RD is not sufficiently understood. Some view IgG4-RD as an allergic disease, because IgG4-RD is often complicated in allergic diseases and serum IgE levels are often high in IgG4-RD. Others see IgG4-RD as an autoimmune disease, because anti-lactoferrin [5] and carbonic anhydrase II [6] antibodies are detected in some of IgG4-related autoimmune pancreatitis cases, and because IgG4-RD cases usually show good responses to glucocorticoid therapies.

\footnotetext{
* Correspondence: yossii@kuhp.kyoto-u.ac.jp

Department of Rheumatology and Clinical Immunology, Graduate School of Medicine, Kyoto University, 54 Shogoin-Kawahara-cho, Sakyo-ku, Kyoto 606-8507, Japan
}

\section{() Biomed Central

At this point, there is no consensus that IgG4-related disease is an autoimmune disorder. To examine whether IgG4 in IgG4-RD is autoreactive, we determined IgG subclasses of serum anti-nuclear antibody (ANA) in IgG4-RD patients and compared them with those in patients with systemic autoimmune diseases such as systemic lupus erythematosus (SLE), Sjögren's syndrome (SS), systemic sclerosis (SSc), and polymyositis (PM). Using a subclass-based ANA test that was derived from indirect immunofluorescence (IIF), we investigated how frequently IgG4 was included in ANA in IgG4-RD. We also examined how frequently each IgG subclass was included in ANA in systemic autoimmune diseases.

\section{Methods \\ Patients}

Patients were recruited from Department of Rheumatology and Clinical Immunology, Kyoto University Hospital, Kyoto, Japan. The patients were definitely diagnosed by the 2011 Comprehensive Diagnostic Criteria proposed by the IgG4-RD research team of Ministry of Health, Labour and Welfare (MHLW), Japan [4]: (1) diffuse or 
localized swelling or mass formation of $\geq 1$ organs, (2) elevated serum IgG4 levels $\geq 135 \mathrm{mg} / \mathrm{dL}$, (3a) fibrosis with remarkable infiltration of lymphocytes and plasma cells, and (3b) $\mathrm{IgG4}^{+} / \mathrm{IgG}^{+}$plasma cell ratio $>0.4$, and $>$ $10 \mathrm{IgG4}^{+}$plasma cells in a high-power field. No IgG4RD patients were considered having SS, Castleman's disease, sarcoidosis, granulomatosis with polyangiitis, or malignant lymphoma. As ANA-positive disease controls, we enrolled 8 SLE patients diagnosed by the 1997 American College of Rheumatology revised criteria [7], 8 SS patients diagnosed by the 1999 revised criteria of MHLW, Japan [8], 4 SSc patients diagnosed by the 1980 American College of Rheumatology criteria [9], and 7 PM patients diagnosed by Bohan and Peter's criteria [10]. All participants provided informed consent in accordance with the Declaration of Helsinki. This study was approved by the Medical Ethics Committee of Graduate School of Medicine and Faculty of Medicine, Kyoto University.

\section{Detection of subclass-specific ANA}

We performed subclass-based ANA tests based on the Fluoro-HepANA ${ }^{\mathrm{Tu}}$ test (Medical \& Biological Laboratories, Nagoya, Japan). Briefly, HEp-2 cell-coated slides were incubated with sera, washed with PBS, incubated with FITC-labeled second antibodies, and observed with a fluorescence microscope. Instead of using anti-total human IgG antibody as the second antibody, we used anti-IgG1 (ab50473, Abcam), anti-IgG2 (10122, Alpha Diagnostic Intl.), anti-IgG3 (10123, Alpha Diagnostic Intl.), or anti-IgG4 antibodies (ab99821, Abcam). To detect total-IgG ANA, patients' sera are usually diluted by the ratios starting from 1:40. To detect each IgG-subclass ANA, the sera were not diluted because of relatively low affinities of the second antibodies against subclasses.

\section{Results}

\section{ANA positivity of IgG4-RD}

Of 19 cases that definitely satisfied the 2011 Comprehensive Diagnostic Criteria for IgG4-RD by MHLW, Japan (Table 1), 14 (74.\%) were older than 60 years, and 14 (74 \%) were male. Lymph node swellings and retroperitoneal fibrosis were major manifestations. Eleven patients (58 \%) were ANA-positive at a cut-off titer of 1:40 (range: 1:40-1:320). The ANA patterns were homogeneous + speckled or speckled in most cases. Although 7 (37\%) were positive for rheumatoid factor and 2 (11\%) were positive for anti-SS-A/Ro antibodies, we confirmed these 9 cases did not fulfill the criteria for rheumatoid arthritis (RA) or SS. No patients were positive for antiDNA, Sm, or U1-RNP antibodies.

Table 1 Clinical, serological, and histopathological features of IgG4-RD cases

\begin{tabular}{|c|c|c|c|c|c|c|c|}
\hline Case & Age & $\operatorname{lgG} 4^{a}$ & $\operatorname{lgG}^{a}$ & ANA Specific Abs & $\mathrm{RF}^{\mathrm{b}}$ & Clinical manifestations & Biopsy source, $\operatorname{lgG} 4^{+} / \operatorname{lgG}^{+}$cell ratio \\
\hline 1 & 73 & 2890 & 3668 & 40 (Homo + Spe) & $<6$ & Mikulicz's disease, Prostatitis, LN & Prostate, 0.60 \\
\hline 2 & 76 & 2210 & 3632 & 40 (Spe) & $<6$ & Mikulicz's disease, RPF & Submandibular gl, 0.40 \\
\hline $3^{c}$ & 79 & 1460 & 3669 & $160\left(\right.$ Homo + Spe) Anti-SS-A ${ }^{+}$ & $<6$ & Küttner's tumor, IP, IN, RPF, LN & Submandibular gl, 0.73 \\
\hline 4 & 66 & 1090 & 2301 & 40 (Homo + Spe) & 30.3 & AIP, IN, Renal pseudotumor & Kidney, 0.70 \\
\hline $5^{c}$ & 73 & 592 & 3321 & 320 (Homo + Spe) & $<6$ & Sialadenitis, IP, IN, RPF, LN & Submandibular gl, 0.43 \\
\hline 6 & 74 & 389 & 2184 & $<40$ & $<6$ & Retroorbital tumor & Retroorbital tumor, 0.48 \\
\hline 7 & 52 & 383 & 1748 & $<40$ & $<6$ & Küttner's tumor & Submandibular gl, 0.57 \\
\hline 8 & 70 & 724 & 1729 & $<40$ & $<6$ & Küttner's tumor, LN & Submandibular gl, 0.40 \\
\hline 9 & 46 & 675 & 1617 & 80 (Homo + Spe) & 26.8 & Mikulicz's disease & Lachrymal gl, 0.41 \\
\hline 10 & 37 & 533 & 1741 & $<40$ & $<6$ & Mikulicz's disease & Lachrymal gl, 0.50 \\
\hline 11 & 76 & 458 & 1527 & $<40$ & $<6$ & AIP, RPF & Retroperitoneal tumor, 0.70 \\
\hline 12 & 62 & 315 & 1809 & 40 (Spe) Anti-SS-A ${ }^{+}$ & $<6$ & AIP, RPF & Pancreas, 0.43 \\
\hline 13 & 79 & 1960 & 2953 & 40 (Homo + Spe) & 65 & Orbital tumor, Lung nodule, LN & Orbital tumor, 0.59 \\
\hline $14^{c}$ & 62 & 1460 & 2177 & 40 (Spe) & 23.3 & Sialadenitis, Laryngeal tumor, LN & Parotid gl, 0.60 Cervical LN, 0.69 \\
\hline 15 & 65 & 1050 & 1811 & $<40$ & 19.8 & Mikulicz's disease, LN & Submandibular LN, 0.80 \\
\hline 16 & 25 & 1210 & 2181 & $<40$ & $<6$ & Mikulicz's disease, IP, IN, Renal pseudotumor, LN & Minor salivary gl, 0.65 \\
\hline 17 & 55 & 1510 & 3116 & $<40$ & 72.2 & Orbital tumor, RPF, Lung nodule, LN & Cervical LN, 0.90 \\
\hline 18 & 61 & 491 & 1466 & 80 (Spe + Granular) & $<6$ & Sialadenitis & Submandibular gl, 0.48 \\
\hline 19 & 78 & 1470 & 3762 & 80 (Homo + Spe) & 35 & AIP, RPF & Vater's ampulla, 0.48 \\
\hline
\end{tabular}

${ }^{\mathrm{a}} \mathrm{mg} / \mathrm{dL}$ in serum. ${ }^{\mathrm{b}} \mathrm{IU} / \mathrm{mL}$. ${ }^{\mathrm{C}}$ Shown in Fig. 1

ANA: anti-nuclear antibody; gl: gland; Homo: homogeneous; IN: interstitial nephritis; IP: interstitial pneumonitis; LN: lymph node; RF: rheumatoid factor; RPF: retroperitoneal fibrosis; Spe: speckled 


\section{IgG subclasses of ANA in IgG4-RD}

We selected 5 IgG4-RD patients robustly ANA-positive with a cut-off titer of 1:80, and examined the IgG subclasses of their ANA. Subclass-based ANA test showed $\mathrm{IgG2}^{+}$ANA and scant IgG1 ${ }^{+}$ANA. However, we found no $\mathrm{IgG}^{+}$or $\mathrm{IgG}^{+}$ANA (Fig. 1, 2). We confirmed that the second antibody against IgG4 worked, using direct immunofluorescence on a lymph node specimen $\left(\operatorname{IgG} 4^{+} / \mathrm{IgG}^{+}\right.$ plasma cell ratio $=0.69$ ) of an IgG4-RD patient (Fig. 1, lower right panel).

\section{IgG subclasses of ANA in systemic autoimmune diseases}

We examined IgG subclasses of ANA in systemic autoimmune diseases such as SLE, SSc, SS, and PM (Table 2). The ANA titers ranged from 1:40 to 1:5120 with various patterns. The Subclass-based ANA test detected $\operatorname{IgG1}{ }^{+}$, $\mathrm{IgG}^{+}$, or $\mathrm{IgG}^{+}$ANA in the systemic autoimmune disease cases (Fig. 2, 3). Especially, all cases were IgG2 ${ }^{+}$. However, IgG4 was not detected (Fig. 2, 3), except in a patient with SS who showed IgG4-type ANA with peripheral pattern (Fig. 4).

\section{An exceptional case with IgG4-type ANA}

A 79-year-old male with SS showed IgG4-type ANA with peripheral pattern (Fig. 4). Lip biopsy results were compatible with SS, although anti-IgG4 staining was not performed. Anti-SS-A/Ro antibody was positive. We saw no swelling of lacrimal glands, salivary glands, or lymph nodes. This patient did not meet the criteria for IgG4$\mathrm{RD}$ and was not considered to have clinical IgG4-RD.

\section{Difference of ANA patterns among IgG subclasses}

In serum from one patient, ANA patterns differed among IgG subclass. Such phenomenon was seen in Fig. 3 and 4 .

\section{Discussion}

In IgG4-RD patients, we found no $\operatorname{IgG4}^{+}$ANA, but did detect $\operatorname{IgG}^{+}$and $\operatorname{IgG}^{+}$ANA (Fig. 1 and 2). We also found $\mathrm{IgG4}^{+}$ANA was very rare, whereas $\operatorname{IgG} 1 / 2 / 3^{+}$ ANA were detected in systemic autoimmune diseases (Fig. 2 and 3). Autoantibodies with cytoplasmic patterns in the Fluoro-HepANA ${ }^{\mathrm{Tm}}$ test are not exact ANA; "anti-cytoplasmic" antibodies-e.g., anti-SS-A/Ro, antiaminoacyl-tRNA synthetase, and anti-signal recognition particle antibodies-are known in SS and PM. Subclass-based ANA tests found $\operatorname{IgG} 1 / 2 / 3^{+}$anticytoplasmic antibodies, but not IgG4 (Fig. 2, 3).

$\mathrm{IgG4}^{+}$ANA is very rare in systemic autoimmune diseases, possibly because serum IgG4/IgG ratios are low, less than $5 \%$, in these diseases (Table 2). However, IgG4 ${ }^{+}$ ANA was not detected despite high serum IgG4/IgG ratios (43 \%) in IgG4-RD. This implies that IgG4 itself is not used to make ANA.

Several studies have investigated ANA subclasses in systemic autoimmune diseases. Zouali et al. reported that in SLE and mixed connective tissue disease, antidouble-stranded DNA (dsDNA) antibody was IgG1/3dominant, and anti-RNP was IgG2-dominant [11]. AntiSm, anti-RNP, and anti-dsDNA in SLE [12], anti-SS-A/ Ro and anti-SS-B/La in SS [13], and anti-Scl-70 in SSc [14] are reportedly IgG1-dominant. However, IgG4-type ANA was hardly detected in all the above reports. Rigopoulou et al. examined primary biliary cirrhosis cases, and found that ANA was IgG1/3-dominant but IgG4 was not detected by subclass-based IIF [15]. The reason IgG2-type ANA was remarkably frequent in our study whereas IgG1 and IgG3 were predominant in previous studies might be that second antibody affinities differed between studies. In the subclass-based ANA test, titers cannot be accurately compared between subclasses, as

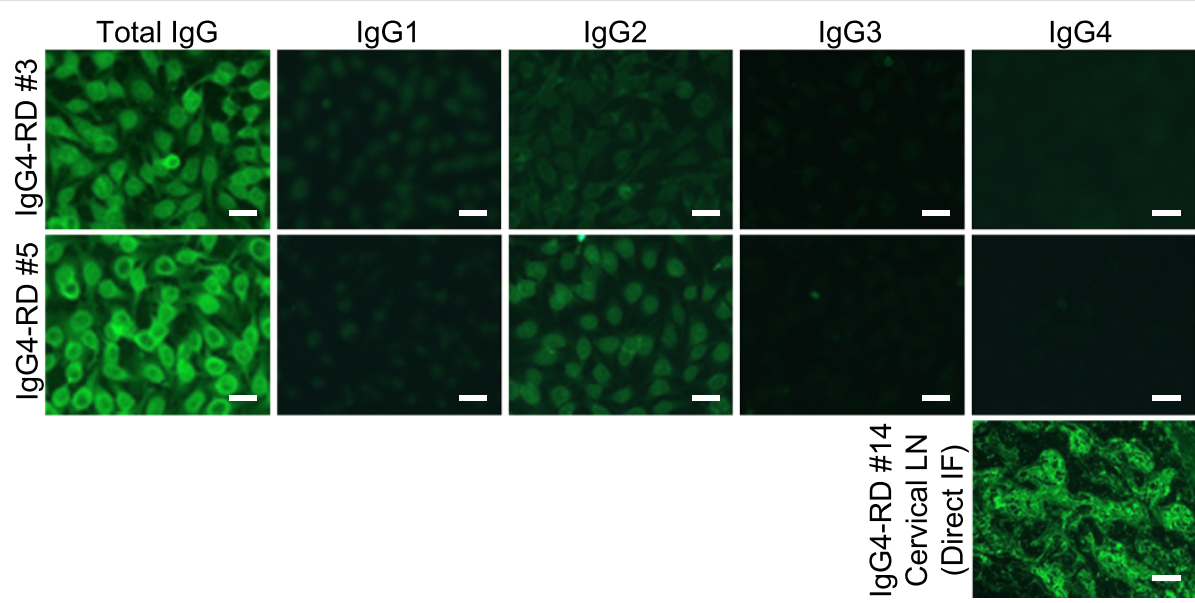

Fig. 1 Subclass-based ANA test in IgG4-RD, showing immunofluorescence microscopy of two typical IgG4-RD cases (lgG4-RD \#3 and \#5). Lower right panel: We confirmed the second antibody's function by direct immunofluorescence of a lymph node specimen (lgG4 ${ }^{+} / \mathrm{lgG}^{+}$plasma cell ratio $=0.69)$ from an IgG4-RD patient (lgG4-RD \#14). Bar $=20 \mu \mathrm{m}$ 


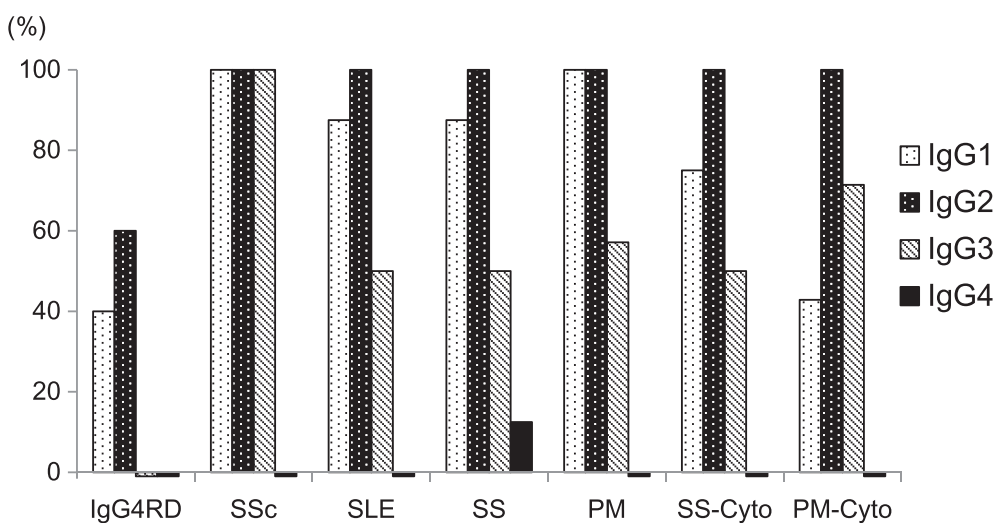

Fig. 2 Positivity of each ANA subclass in IgG4-RD and systemic autoimmune diseases. Cyto: positivity of each subclass of anti-cytoplasmic antibody was also calculated for patients with Sjögren's syndrome and polymyositis

Table 2 ANA profiles of patients with systemic autoimmune diseases

\begin{tabular}{|c|c|c|c|c|}
\hline Case & ANA & Specific autoantibodies & $\lg G 4^{a}$ & $\lg G^{a}$ \\
\hline$\overline{S L E} 1^{\mathrm{b}}$ & Spe 320 & dsDNA, ssDNA, U1-RNP, Sm & 21.3 & 1830 \\
\hline SLE 2 & Homo + Spe 320 & dsDNA, ssDNA, SS-A & 11 & 826 \\
\hline SLE 3 & Spe 1280 & dsDNA, ssDNA, Sm, Ribosome & 20 & 2043 \\
\hline SLE 4 & Spe 640 & ssDNA, U1-RNP, Sm, SS-A, SS-B & 8.3 & 829 \\
\hline SLE 5 & Homo + Spe 1280 & dsDNA, ssDNA, U1-RNP, Sm, SS-A, SS-B & 7 & 556 \\
\hline SLE 6 & Homo + Spe 160 & ssDNA & 48.6 & 1938 \\
\hline SLE 7 & Spe 320 & dsDNA, SS-A & 19.6 & 1186 \\
\hline SLE 8 & Spe 5120 & dsDNA, ssDNA, U1-RNP, Sm, SS-A & 7 & 908 \\
\hline SSC 1 & Discrete spe 1280 & Centromere & 7 & 1177 \\
\hline $\operatorname{SSC} 2^{b}$ & Discrete spe 1280, Spe 160, Cyto 80 & Centromere, SS-A & 21.2 & 1772 \\
\hline $\operatorname{sSc} 3$ & Spe 1280 & Scl-70, U1-RNP, SS-A & 25.5 & 2147 \\
\hline SSc 4 & Discrete spe 1280 & Centromere, Scl-70, U1-RNP & 12.4 & 1108 \\
\hline SS 1 & Spe 320 & SS-A, SS-B & 33.4 & 2974 \\
\hline SS 2 & Spe 160 & SS-A, SS-B & 16.5 & 1765 \\
\hline SS 3 & Spe 80 & SS-A, SS-B & 74 & 1370 \\
\hline $\operatorname{SS} 4^{c}$ & Spe 640 & SS-A & 228 & 1721 \\
\hline SS 5 & Spe 40, Cyto 80 & SS-A & 38 & 2133 \\
\hline SS 6 & Spe 160 & SS-A, SS-B & 14.5 & 2340 \\
\hline SS 7 & Spe 160 & SS-A, SS-B & 9.5 & 1882 \\
\hline $\operatorname{SS} 8^{b}$ & Spe + Nucleolar 80, Cyto 40 & SS-A & 20.1 & 1678 \\
\hline PM 1 & Spe + Nucleolar 640 & $\mathrm{Ku}$ & 53.5 & 1668 \\
\hline $\mathrm{PM} 2^{\mathrm{b}}$ & Spe 320 , Cyto 40 & ssDNA, U1-RNP, Sm, SS-A & 12.9 & 1132 \\
\hline PM 3 & Spe 40, Cyto 160 & PL-7 & 15 & 717 \\
\hline PM 4 & Spe 320 & U1-RNP, Sm & 5 & 282 \\
\hline PM 5 & Spe 1280 & Ku, SS-A, SS-B & $<3$ & 823 \\
\hline PM 6 & Spe 40, Cyto 80 & SRP & 18.4 & 1365 \\
\hline PM 7 & Homo + Spe 160 & Not detected & 19 & 2051 \\
\hline
\end{tabular}

${ }^{\mathrm{a}} \mathrm{mg} / \mathrm{dL}$ in serum. ${ }^{\mathrm{b}}$ Shown in Fig. 3. ${ }^{\text {CShown in Fig. } 4}$

ANA: anti-nuclear antibody; Cyto: cytoplasmic; Discrete spe: discrete speckled; Homo: homogeneous; RNP: ribonucleoprotein; Spe: speckled; SRP: signal recognition particle 

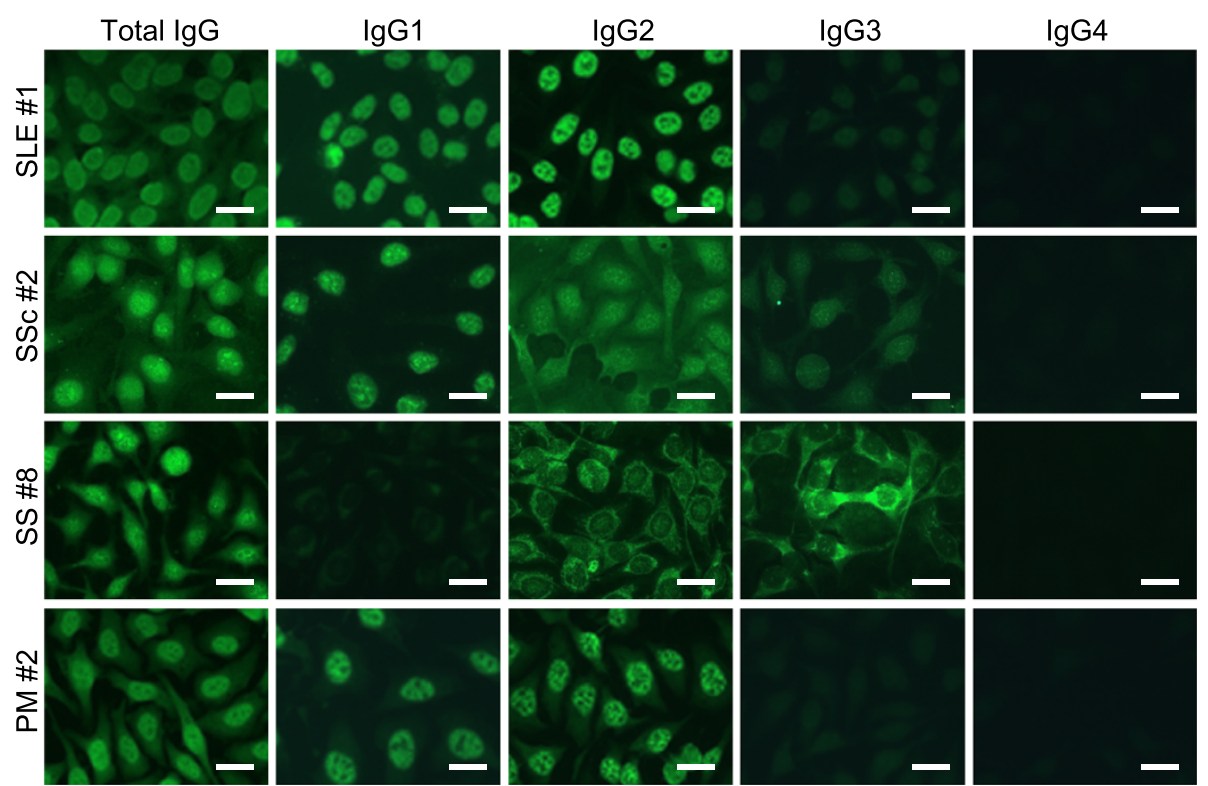

Fig. 3 Subclass-based ANA test for systemic autoimmune diseases showing immunofluorescence microscopy for each typical case, including systemic lupus erythematosus (SLE \#1), systemic sclerosis (SSC \#2), Sjögren's syndrome (SS \#8) and polymyositis (PM \#2) showed variation in ANA patterns among IgG subclasses. In SSC \#2, total IgG showed Discrete spe + Speckled + Cyto, while lgG1 showed Discrete spe + Speckled, lgG2 showed Discrete spe + Speckled + Cyto, lgG3 showed Discrete spe + Cyto, and IgG4 showed negative. In SS \#8, total lgG showed Speckled + Nucleolar + Cyto, while IgG1 and IgG2 showed Speckled + Cyto, lgG3 showed Nucleolar + Cyto, and IgG4 showed negative. Bar = $20 \mu \mathrm{m}$ Discrete spe: discrete speckled, Cyto: cytoplasmic

the second antibodies are different. In past studies, IgG2-type ANA was also detected at moderate levels, whereas IgG4-type ANA was constantly negative or at low levels. In our study, IgG4-type ANA was also hardly detected.

Autoimmune pancreatitis (AIP) is an organ-specific disorder seen in IgG4-RD. Various autoantibodies, such as anti-lactoferrin [5] and anti-carbonic anhydrase II [6] antibodies, are seen in AIP. Asada et al. found antipancreatic secretory trypsin inhibitor (PSTI) antibody in AIP, and showed that the titers of anti-PSTI antibody moved in parallel with serum IgG4 levels [16]. IgG4 levels change in parallel with IgG4-RD disease activity, as reported in many studies, including our previous study [17]. Asada et al. thought that anti-PSTI might be an important factor in the pathophysiology. However, immunoblotting of subclasses with anti-IgG1 or antiIgG4 as second antibodies showed the subclass was not IgG4 but IgG1. Possibly, IgG4-type autoantibodies are difficult to produce in IgG4-RD patients.

However, some autoimmune diseases reportedly show IgG4-type autoantibodies. Rock et al. reported that IgG4

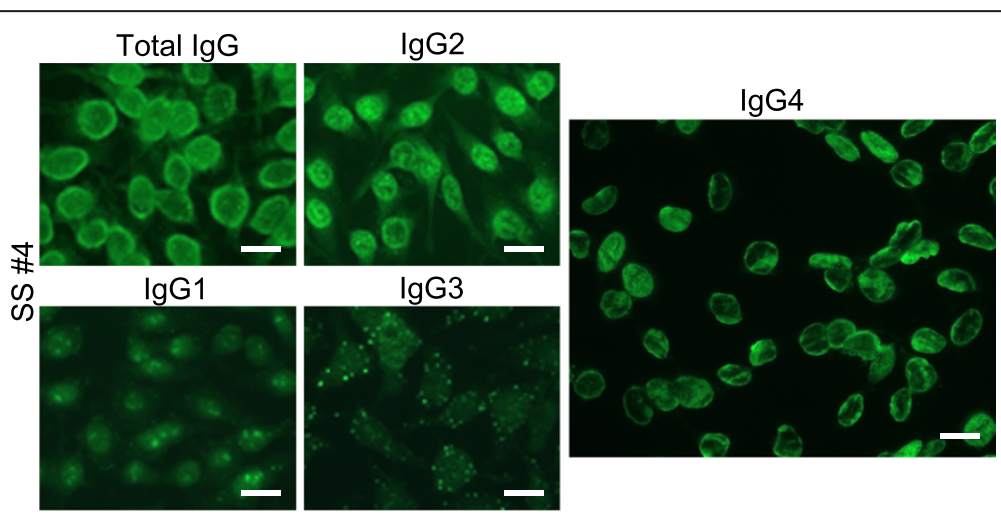

Fig. 4 Subclass-based ANA test of a patient with Sjögren's syndrome (SS \#4) showing IgG4-type ANA. ANA patterns differed among IgG subclasses. Total lgG showed Speckled, while lgG2 showed Speckled + Cyto, lgG1 and lgG3 showed Nucleolar + Cyto (with atypical cytoplasmic spots), and lgG4 showed Peripheral. Bar $=20 \mu \mathrm{m}$. Cyto: cytoplasmic 
was the most common (100 \%) of anti-desmoglein (Dsg)-1 antibodies detected in sera of patients with pemphigus foliaceus, and showed the pathogenicity of IgG4-type anti-Dsg-1 antibody using Balb/c mice [18]. Anti-Dsg-3 antibody in pemphigus vulgaris was also IgG4-predominant [19]. Beck et al. showed by immunoblotting that anti-phospholipase $\mathrm{A}_{2}$ receptor $\left(\mathrm{PLA}_{2} \mathrm{R}\right)$ antibody in idiopathic membranous nephropathy mainly consisted of IgG4 [20]. IgG4 is reportedly predominant in anti-neutrophil cytoplasmic antibody (ANCA). C-ANCA (IIF), proteinase-3 (PR3)-ANCA (ELISA), and myeloperoxidase (MPO)-ANCA (ELISA) in granulomatosis with polyangiitis (GPA) [21], and MPO-ANCA (ELISA) in propylthiouracil-induced vasculitis [22] were IgG1/4dominant. Others similarly reported that IgG4 made up most C-ANCA (IIF) and PR3-ANCA (ELISA) in vasculitides [23, 24]. Engelmann et al. reported that anti-cyclic citrullinated peptide (CCP) antibody was IgG1/4dominant in RA [25]. However, IgG4 in vasculitides and RA might not be pathophysiologically important. In functional analyses of ANCA, IgG1 and IgG3 PR3ANCA can stimulate neutrophils [26], whereas IgG4 PR3-ANCA was only weakly stimulatory to neutrophils [27]. In RA patients who had HLA-DR4-shared epitope, Engelmann et al. found IgG3 anti-CCP antibody to be predominant, and considered that IgG3-type antibody might be more important in the pathophysiology of RA [28]. As IgG4 has poor ability to activate complements and antibody-dependent cellular cytotoxicity [29-32], IgG4 is unlikely to take part in mechanisms of tissue damage in autoimmune diseases.

Interestingly, there seem to be pathogenic and nonfunctional IgG4-type autoantibodies. IgG4-type ANCA is considered less pathogenic, compared to other subclass ANCA in ANCA-associated vasculitis [26, 27]. The affinities between IgG4-type and other subclass ANCA should be equal, but the abilities of complement activation are different, so that the role of IgG4-type ANCA can be less significant than that of other subclass ANCA. On the other hand, IgG4 anti-PLA ${ }_{2} \mathrm{R}$ antibody has high affinity and is considered pathogenic in idiopathic membranous nephropathy [20]. Why IgG4 anti-PLA ${ }_{2} \mathrm{R}$ antibody can exert pathogenicity without ability of complement activation may be because the pathogenicity is brought by the destruction of electrical barriers of glomerular basement membrane.

Taken together, IgG4 usage rates differ among autoantibodies and among diseases. IgG4 is associated with anti-Dsg-1/3, anti-PLA ${ }_{2} \mathrm{R}$, anti-CCP antibodies, and ANCA, but not with anti-PTSI antibody in AIP or ANA in IgG4-RD and systemic autoimmune diseases (Table 3). This asymmetry implies that IgG4 has unknown but certain physiological or pathological functions. Further analyses are needed to know its role.

In the present study, we observed ANA patterns differed among IgG subclasses in some cases (Fig. 3, 4). When a case has several autoantibodies, the utilized subclasses differ by autoantigens. This can be explained by the hypothesis that each IgG subclass prefers to cover its own spectrum of antigens. The reason we hardly found IgG4 in ANA might be that IgG4 does not cover antigens that can be detected by the ANA test-i.e., nuclear antigens or related microbial antigens. Selective IgG2 subclass deficiency is often associated with bacterial infection by Neisseria meningitidis and Streptococcus pneumoniae [33, 34], so that IgG2 is considered to have a role in protection from these bacteria. The role of IgG4 has not been sufficiently understood. If IgG4 is related to some microorganism type, and if the microorganism antigens and autoantigens are similar, as with Dsg- $1 / 3$, $\mathrm{PLA}_{2} \mathrm{R}, \mathrm{PR} 3$, and citrullinated proteins, it would explain why IgG4-type antibody against those proteins was dominantly generated.

Our results imply that IgG4-RD is not an autoimmune disease, and that high levels of serum IgG4 in IgG4-RD are only nonspecific. Subclass-based ANA tests in this study covered both nuclear and cytoplasmic antigens in HEp-2 cells, and can screen a wide range of unmodified ubiquitous antigens. However, this analysis has limitations: modified antigens like citrullinated proteins and

Table 3 Summary of predominant subclasses in autoantibodies in IgG4-RD and autoimmune diseases

\begin{tabular}{lllll}
\hline Diseases & Autoantibodies & Predominant subclass & lgG4 subclass & Reports \\
\hline $\operatorname{lgG} 4-\mathrm{RD}$ & ANA & $\operatorname{lgG} 2$ & Negative & Present study \\
$\operatorname{lgG4-RD}($ AIP) & Anti-PSTI & $\operatorname{lgG} 1$ & Negative & Asada [16] \\
SLE, SSc, SS, PM & ANA & $\operatorname{lgG} 1 / 2 / 3$ & Seldom & Present study, Zouali [1 1], Eisenberg [12], Maran [13], Vazquez-abad [14] \\
GPA, Vasculitis & ANCA & $\operatorname{lgG} 1, \operatorname{lgG} 4$ & Frequent & Brouwer [21], Mellbye [23], Liu [24], Gao [22] \\
RA & ACPA & $\operatorname{lgG1}, \operatorname{lgG4}$ & Frequent & Engelmann [25] \\
PF, PV & Anti-Dsg-1/3 & $\operatorname{lgG} 4$ & Primary & Rock [18], Ding [19] \\
Idiopathic MN & Anti-PLA 2 R & $\operatorname{lgG4}$ & Primary & Beck [20] \\
\hline
\end{tabular}

ACPA: anti-citrullinated protein antibody; AIP: autoimmune pancreatitis; ANA: anti-nuclear antibody; ANCA: anti-neutrophil cytoplasmic antibody; Dsg-1/3: desmoglein-1 and 3; GPA: granulomatosis with polyangiitis; MN: membranous nephropathy; PF: pemphigus foliaceus; PLA 2 : phospholipase $A_{2}$ receptor; PSTI: pancreatic secretory trypsin inhibitor; PV: pemphigus vulgaris; RA: rheumatoid arthritis 
organ-specific antigens are not screened. The number of cases is limited in this study. There remains a possibility that unknown IgG4-type autoantibodies might be found in IgG4-RD. A further analysis is needed.

\section{Conclusions}

We found ANA in IgG4-RD patients are not IgG4-based despite high serum IgG4 levels. IgG4 was also hardly found in ANA in systemic autoimmune diseases. We also observed several patients in whom ANA patterns differed among IgG subclasses, probably due to difference in corresponding autoantigens. These findings imply that each IgG subclass tends to cover its own spectrum of antigens, and IgG4 is not apparently used to make ANA.

\section{Abbreviations}

ANA: Anti-nuclear antibody; ANCA: Anti-neutrophil cytoplasmic antibody; AIP: Autoimmune pancreatitis; CCP: Cyclic citrullinated peptides; dsDNA: Doublestranded deoxyribonucleic acid; Dsg: Desmoglein; ELISA: Enzyme-linked immunosorbent assay; GPA: Granulomatosis with polyangiitis; HLA: Human leukocyte antigen; lgG4-RD: Immunoglobulin G4-related disease; IIF: Indirect immunofluorescence; MPO: Myeloperoxidase; PLA 2 R: Phospholipase $A_{2}$ receptor; PM: Polymyositis; PR3: Proteinase-3; PTSI: Pancreatic secretory trypsin inhibitor: RA: Rheumatoid arthritis; RNP: ribonucleoprotein; SLE: Systemic lupus erythematosus; SS: Sjögren's syndrome; SSc: Systemic sclerosis.

\section{Competing interests}

The authors declare that they have no competing interests.

\section{Authors' contributions}

TM provided the idea of IgG4-subclass autoantibody in IgG4-RD. K. Kiyama and HY designed the study and collected the clinical data. K. Kiyama, HY, TK, and RN performed experiments and evaluations. DK gave significant suggestions and advice to the study. All the authors contributed to the composition of the manuscript.

\section{Acknowledgements}

This study was supported by a grant for Research Program for Intractable Disease (the IgG4-related disease research team) from Ministry of Health, Labour and Welfare, Japan.

\section{Received: 20 January 2014 Accepted: 18 May 2015}

Published online: 28 May 2015

\section{References}

1. Masaki Y, Dong L, Kurose N, Kitagawa K, Morikawa Y, Yamamoto M, et al. Proposal for a new clinical entity, lgG4-positive multiorgan lymphoproliferative syndrome: analysis of 64 cases of IgG4-related disorders. Ann Rheum Dis. 2009:68(8):1310-5.

2. Okazaki K, Uchida K, Miyoshi H, Ikeura T, Takaoka M, Nishio A. Recent concepts of autoimmune pancreatitis and IgG4-related disease. Clin Rev Allergy Immunol. 2011:41(2):126-38.

3. Umehara H, Okazaki K, Masaki Y, Kawano M, Yamamoto M, Saeki T, et al. A novel clinical entity, IgG4-related disease (IgG4RD): general concept and details. Mod Rheumatol. 2012;22(1):1-14

4. Umehara H, Okazaki K, Masaki Y, Kawano M, Yamamoto M, Saeki T, et al. Comprehensive diagnostic criteria for lgG4-related disease (IgG4-RD), 2011. Mod Rheumatol. 2012;22(1):21-30.

5. Okazaki K, Uchida K, Ohana M, Nakase H, Uose S, Inai M, et al. Autoimmunerelated pancreatitis is associated with autoantibodies and a Th1/Th2-type cellular immune response. Gastroenterology. 2000;118(3):573-81.

6. Nishi H, Tojo A, Onozato ML, Jimbo R, Nangaku M, Uozaki H, et al. Anticarbonic anhydrase II antibody in autoimmune pancreatitis and tubulointerstitial nephritis. Nephrol Dial Transplant. 2007;22(4):1273-5.
7. Hochberg MC. Updating the American College of Rheumatology revised criteria for the classification of systemic lupus erythematosus. Arthritis Rheum. 1997;40(9):1725.

8. Fujibayashi T, Sugai S, Miyasaka N, Hayashi Y, K T: Revised Japanese criteria for Sjögren's syndrome (1999): availability and validity. Mod Rheumatol 2004(14):425-434.

9. Preliminary criteria for the classification of systemic sclerosis (scleroderma). Subcommittee for scleroderma criteria of the American Rheumatism Association Diagnostic and Therapeutic Criteria Committee. Arthritis Rheum 1980, 23(5):581-590.

10. Bohan A, Peter JB. Polymyositis and dermatomyositis (first of two parts). N Engl J Med. 1975;292(7):344-7.

11. Zouali M, Jefferis R, Eyquem A. IgG subclass distribution of autoantibodies to DNA and to nuclear ribonucleoproteins in autoimmune diseases. Immunology. 1984;51(3):595-600.

12. Eisenberg RA, Dyer $K$, Craven SY, Fuller CR, Yount WJ. Subclass restriction and polyclonality of the systemic lupus erythematosus marker antibody anti-Sm. J Clin Invest. 1985;75(4):1270-7.

13. Maran R, Dueymes M, Pennec YL, Casburn-Budd R, Shoenfeld Y, Youinou P. Predominance of IgG1 subclass of anti-Ro/SSA, but not anti-La/SSB antibodies in primary Sjogren's syndrome. J Autoimmun. 1993;6(3):379-87.

14. Vazquez-Abad D, Monteon V, Senecal JL, Walsh S, Rothfield N. Analysis of IgG subclasses of human antitopoisomerase I autoantibodies suggests chronic B cell stimulation. Clin Immunol Immunopathol. 1997;84(1):65-72.

15. Rigopoulou El, Davies ET, Pares A, Zachou K, Liaskos C, Bogdanos DP, et al. Prevalence and clinical significance of isotype specific antinuclear antibodies in primary biliary cirrhosis. Gut. 2005;54(4):528-32.

16. Asada M, Nishio A, Uchida K, Kido M, Ueno S, Uza N, et al. Identification of a novel autoantibody against pancreatic secretory trypsin inhibitor in patients with autoimmune pancreatitis. Pancreas. 2006;33(1):20-6.

17. Kiyama K, Kawabata D, Hosono Y, Kitagori K, Yukawa N, Yoshifuji H, et al. Serum BAFF and APRIL levels in patients with lgG4-related disease and their clinical significance. Arthritis Res Ther. 2012;14(2):R86.

18. Rock B, Martins CR, Theofilopoulos AN, Balderas RS, Anhalt GJ, Labib RS, et al. The pathogenic effect of IgG4 autoantibodies in endemic pemphigus foliaceus (fogo selvagem). N Engl J Med. 1989;320(22):1463-9.

19. Ding X, Aoki V, Mascaro Jr JM, Lopez-Swiderski A, Diaz LA, Fairley JA. Mucosal and mucocutaneous (generalized) pemphigus vulgaris show distinct autoantibody profiles. J Invest Dermatol. 1997;109(4):592-6.

20. Beck Jr LH, Bonegio RG, Lambeau G, Beck DM, Powell DW, Cummins TD, et al. M-type phospholipase A2 receptor as target antigen in idiopathic membranous nephropathy. N Engl J Med. 2009;361(1):11-21.

21. Brouwer E, Tervaert JW, Horst G, Huitema MG, van der Giessen M, Limburg PC, et al. Predominance of lgG1 and lgG4 subclasses of anti-neutrophil cytoplasmic autoantibodies (ANCA) in patients with Wegener's granulomatosis and clinically related disorders. Clin Exp Immunol. 1991;83(3):379-86.

22. Gao Y, Ye H, Yu F, Guo XH, Zhao MH. Anti-myeloperoxidase lgG subclass distribution and avidity in sera from patients with propylthiouracil-induced antineutrophil cytoplasmic antibodies associated vasculitis. Clin Immunol. 2005:117(1):87-93.

23. Mellbye OJ, Mollnes TE, Steen LS. IgG subclass distribution and complement activation ability of autoantibodies to neutrophil cytoplasmic antigens (ANCA). Clin Immunol Immunopathol. 1994;70(1):32-9.

24. Liu LJ, Chen M, Yu F, Zhao MH, Wang HY. IgG subclass distribution, affinity of anti-myeloperoxidase antibodies in sera from patients with Wegener's granulomatosis and microscopic polyangiitis. Nephrology. 2008;13(7):629-35.

25. Engelmann R, Brandt J, Eggert M, Karberg K, Krause A, Neeck G, et al. IgG1 and lgG4 are the predominant subclasses among auto-antibodies against two citrullinated antigens in RA. Rheumatology (Oxford). 2008;47(10):1489-92.

26. Holland M, Hewins P, Goodall M, Adu D, Jefferis R, Savage CO. Antineutrophil cytoplasm antibody lgG subclasses in Wegener's granulomatosis: a possible pathogenic role for the lgG4 subclass. Clin Exp Immunol. 2004;138(1):183-92.

27. Hussain A, Pankhurst T, Goodall M, Colman R, Jefferis R, Savage CO, et al. Chimeric lgG4 PR3-ANCA induces selective inflammatory responses from neutrophils through engagement of Fcgamma receptors. Immunology. 2009;128(2):236-44.

28. Engelmann R, Eggert M, Neeck G, Mueller-Hilke B. The impact of HLA-DRB alleles on the subclass titres of antibodies against citrullinated peptides. Rheumatology (Oxford). 2010;49(10):1862-6. 
29. van der Zee JS, van Swieten P, Aalberse RC. Inhibition of complement activation by IgG4 antibodies. Clin Exp Immunol. 1986;64(2):415-22.

30. Jefferis R, Reimer CB, Skvaril F, de Lange G, Ling NR, Lowe J, et al. Evaluation of monoclonal antibodies having specificity for human lgG sub-classes: results of an IUIS/WHO collaborative study. Immunol Lett. 1985;10(3-4):223-52.

31. van der Neut KM, Schuurman J, Losen M, Bleeker WK, Martinez-Martinez P, Vermeulen $\mathrm{E}$, et al. Anti-inflammatory activity of human $\lg \mathrm{G} 4$ antibodies by dynamic Fab arm exchange. Science. 2007;317(5844):1554-7.

32. Aalberse RC, Schuurman J. IgG4 breaking the rules. Immunology. 2002;105(1):9-19.

33. Hammarstrom L, Smith Cl. IgG subclasses in bacterial infections. Monogr Allergy. 1986;19:122-33.

34. Escobar-Perez X, Dorta-Contreras AJ, Interian-Morales MT, Noris-Garcia E, Ferra-Valdes M. IgG2 immunodeficiency: association to pediatric patients with bacterial meningoencephalitis. Arq Neuropsiquiatr. 2000;58(1):141-5.

\section{Submit your next manuscript to BioMed Central and take full advantage of:}

- Convenient online submission

- Thorough peer review

- No space constraints or color figure charges

- Immediate publication on acceptance

- Inclusion in PubMed, CAS, Scopus and Google Scholar

- Research which is freely available for redistribution 